\title{
Validation of the PAM-13 instrument in the Hungarian general population 40 years old and above
}

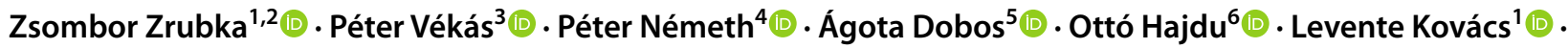 \\ László Gulácsi ${ }^{1,2}$. Judith Hibbard ${ }^{7}$ (1) Márta Péntek ${ }^{1}$ (D)
}

Received: 21 May 2021 / Accepted: 11 January 2022 / Published online: 31 January 2022

(c) The Author(s) 2022

\begin{abstract}
Background Patient activation comprises the skills, knowledge and motivation necessary for patients' effective contribution to their care. We adapted and validated the 13-item Patient Activation Measure (PAM-13) in the $\geq 40$ years old Hungarian general population.

Methods A cross-sectional web survey was conducted among 900 respondents selected from an online panel via quota sampling. After 10 days, the survey was repeated on 100 respondents. The distribution, internal consistency, test-retest reliability, factor structure, convergent, discriminant and known-groups validity of PAM-13 were assessed according to the COSMIN guidelines.

Results The sample comprised 779 respondents. Mean $( \pm$ SD) age was $60.4 \pm 10.6$ years, $54 \%$ were female and $67 \%$ had chronic illness. Mean $( \pm$ SD) PAM-13 score was $60.6 \pm 10.0$. We found good internal consistency (Cronbach alpha: 0.77), moderate test-retest reliability (ICC: $0.62 ; n=75$ ), a single-factor structure and good content validity: PAM-13 showed moderate correlation with the eHealth Literacy Scale $(r=0.40)$, and no correlation with age $(r=0.02)$, education $(r=0.04)$ or income $(\rho=0.04)$. Higher PAM-13 scores were associated with fewer lifestyle risks $(p<0.001)$, more frequent health information seeking $(p<0.001)$, participation in patient education $(p=0.018)$ and various online health-related behaviours. When controlling for health literacy, sociodemographic factors and health status, the association of higher PAM-13 scores with overall fewer lifestyle risks, normal body mass index, physical activity and adequate diet remained significant. Similar properties were observed in the subgroup of participants with chronic morbidity, but not in the age group 65+.

Conclusion PAM-13 demonstrated good validity in the general population. Its properties in clinical populations and the elderly as well as responsiveness to interventions warrant further research.
\end{abstract}

Keywords PAM-13 $\cdot$ Patient activation $\cdot$ eHEALS $\cdot$ Health literacy $\cdot$ Lifestyle-related risks $\cdot$ Online survey $\cdot$ Psychometric validation $\cdot \mathrm{I} 10$

JEL Classification I10

Zsombor Zrubka

zrubka.zsombor@uni-obuda.hu

1 University Research and Innovation Center, Óbuda University, Bécsi út 96/b, Budapest 1034, Hungary

2 Corvinus Institute for Advanced Studies, Corvinus University of Budapest, Fővám tér 8, Budapest 1093, Hungary

3 Institute of Mathematical Statistics and Modelling, Corvinus University of Budapest, Fővám tér 8, Budapest 1093, Hungary

4 Doctoral School of Economics, Business and Informatics, Corvinus University of Budapest, Fővám tér 8 , Budapest 1093, Hungary
5 Centre for Foreign Language Education and Research, Corvinus University of Budapest, Fővám tér 8, Budapest 1093, Hungary

6 Institute of Business Economics, Eötvös Loránd University, Rákóczi út 7, Budapest 1088, Hungary

7 Health Policy Research Group, University of Oregon, 1209 University of Oregon, Eugene, OR 97403-1209, USA 


\section{Background}

In our days more and more people live with chronic conditions, which will account for nearly three quarters of global mortality in 2020 [1]. The quest for sustainable financing of healthcare systems needs to embrace efficient approaches in the management of chronic conditions [2]. Over the last decades, patient centredness has gained considerable attention in medicine, which, by putting patients' values and preferences in the forefront of medical decision-making, aims for their more efficient involvement as partners in the health production process [3, 4]. The monitoring of patient-reported outcomes (PROs) is becoming a strategic priority for healthcare systems [5]. Self-reported health, disability and chronic morbidity (measured by the Minimum European Health Module, MEHM) are now routinely collected in Europe-wide harmonised statistical surveys $[6,7]$. The active involvement of patients is particularly important in the reduction of modifiable lifestylerelated risks, which contribute to a considerable share of excess mortality from chronic conditions [8]. Large-scale policy measures, such as changes of income or education, that can influence important individual determinants of health and healthy behaviours potentially span in time over generations. Therefore, personally acquired potentials, which can develop over later courses of life, such as knowledge, skills, positive emotions and engagement are of particular importance from both public health and health economic perspective $[9,10]$. A number of theories, such as internal locus of control [11], self-efficacy [12], self-management [13] or the transtheoretical model of change [14], have addressed the drivers of change in health behaviours, and a number care delivery models, such as the Chronic Care Model, promoted systematic improvements involving patient centredness, support for self-management, evidence-based proactive interventions, integrated team care and supportive information technology solutions [15]. Digital health interventions have been shown to be effective in promoting healthy behaviours through patient education or supporting behaviour change, and upon the demonstration of adequate supportive evidence, authorities are now considering their adoption among publicly financed health technologies $[16,17]$.

The knowledge component of patients' potential for their effective contribution to health production is usually conceptualised as health literacy: "the degree to which individuals have the ability to find, understand, and use information and services to inform health-related decisions and actions for themselves and others" [18]. Electronic health literacy also involves the skills to appraise information from electronic sources [19]. Health literacy can be assessed from objective performance (e.g. Newest
Vital Sign, NVS) [20] self-reported skills (e.g. Electronic Health Literacy Scale, eHEALS) [19] or indirectly from self-reported behaviours [21]. Although the association between health literacy and mortality benefits has been shown, the evidence concerning its association with better health outcomes or healthy behaviours in chronic conditions is mixed [22, 23].

The concept of patient activation encompasses a broad range of elements beyond health literacy, that enable patients to become effective and informed managers of their health [24]. Patient activation and health literacy are moderately correlated and contribute differently to outcomes [25]. The Patient Activation Measure (PAM) has been developed to serve as a reliable tool that can measure the skills, knowledge and motivation of patients that are necessary for their effective contribution to their own care, and eventually predict better outcomes [24]. While health literacy is associated with better understanding and use of information for making informed choices, patient activation is more strongly associated with healthy behaviours and outcomes [25]. Since its development, PAM has become an officially adopted patient-reported outcome measure (PROM) by the National Institute of Health of the US and the National Health Service of the UK. Its validated versions have been available in over 20 countries and it has been applied in over 500 studies worldwide [26]. It has been demonstrated that higher PAM values are associated with better health outcomes [27], fewer lifestylerelated risks [28], better adherence to therapy [29] and lower use of healthcare resources [28, 30]. Furthermore, it has been shown that patient activation can be improved via digital health interventions $[31,32]$ as well as offline patient support programmes [33].

In accordance with national policies aiming to reduce lifestyle-related excess mortality as well as the advancement of digital health [34], our aim was to adapt and validate the 13-item PAM-13 tool in the Hungarian general population to serve as a widely tested and internationally recognised instrument in the development or monitoring of evidence-based health promotion interventions. In addition to assessing its psychometric properties, we aimed to establish the validity of PAM-13 by demonstrating its association with self-reported skills and behaviours that are expected to signal the effective contribution of individuals to their own health or health care. Specifically, we tested whether higher scores of PAM-13 are positively associated with health literacy, health preventive behaviours, healthier lifestyle as well as engagement with health information seeking, patient education and online health behaviours, such as health-related communication, health information seeking or participation in disease prevention or disease management programmes. 


\section{Methods}

\section{Study design and participants}

In April 2020 we conducted an online survey recruiting 900 respondents aged $\geq 40$ years from a large online panel via quota-based sampling with strata set according to the 2011 population census [35]. As multiple PAM-13 items inquire experiences related to medical care or disease management, we omitted younger adults from the sample to ensure sufficiently high proportion of valid responses (see below). Our sample was representative of the Hungarian population in terms of age groups, gender, education, geographic region and type of settlement. After 10 days, 100 respondents were randomly selected for repeated administration of the entire survey. We considered 10 days lag sufficient to prevent recall while capturing a stable PAM13 status [36-38]. Ethical approval was granted by the National Medical Research Council (TUKEB, ID: 497023/2019/EKU) and a research license was obtained for PAM-13. Recruitment and data collection were performed by an online research company; all participants provided consent prior completing the survey.

\section{Measurement tools and survey items}

\section{PAM-13 and development of the Hungarian language version}

PAM assesses one's knowledge, skill and confidence for self-management. The original version consisted of 22 items. The short version PAM-13 instrument consists of 13 items, scored on a 4-point Likert scale and a $5^{\text {th }}$ 'not applicable' option (Online Resource 1). For a valid PAM13 score, up to 3 'not applicable' responses were allowed. Using a proprietary scoring algorithm based on Rasch analysis, PAM-13 is scored on a scale of $0-100$, where lower values suggest less likelihood that patients engage in effective self-management. Based on their PAM-13 scores, patients can be grouped into four PAM-13 levels. At level 1, patients may not understand the need to take active role in their health. At level 2, their confidence or skill is probably too low to take action. At level 3, patients are beginning to take action, and at level 4 , they may endure in self-management even in difficult times [24, 39, 40]. In this analysis, we use both the $0-100$ score and the 4 levels of activation.

The Hungarian language version of the PAM-13 questionnaire was produced in accordance with the WHO guidelines for the translation and adaptation of instruments [41]. Forward translation was performed by two independent experts and the back translation was carried out by two bilingual translators and elaborated by two researchers (DÁ and ZZ) against the original version of the instrument. The draft instrument was piloted along with cognitive debriefing on 10 respondents, including both males $(N=3)$ and females $(N=7)$, from different age groups (mean \pm SD age $46.8 \pm 16.9$ years). The literal translations were overridden at several questions with natural phrases that were considered to be acceptable for the broadest audience, yet conceptually equivalent with the original questionnaire. The pre-final version was consulted with the developers of the PAM instrument. The 4-level Likert scale response options of the original instrument ("Disagree strongly", "Disagree", "Agree", "Agree strongly") were slightly modified to mark more precisely the scale degrees in a Hungarian context ("Completely disagree", "Rather disagree", "Rather agree", "Completely agree"). The Hungarian PAM-13 is attached in Online Resource 1.

\section{EHEALS}

The eHealth Literacy Scale (eHEALS) measures selfreported eHealth literacy using eight 5 -point Likert scale items. The eHEALS score (range $8-40$ ) is calculated by summing individual item scores, with higher values indicating greater skill levels. The Hungarian eHEALS instrument has been validated in the general population via an online survey [19, 42]. Since eHEALS showed weak correlation with objective performance tests [43, 44], we also measured performed health literacy in our survey.

\section{Newest vital sign}

The newest vital sign (NVS) is a frequently used screening instrument for performed health literacy. Respondents need to answer six questions by interpreting the information from an ice cream nutritional label and performing simple arithmetic tasks. For some questions correct answers can be formulated in several ways. The number of correctly answered items is counted. A score of $0-1$ indicates limited, 2-3 indicated probably limited and 4-6 indicates adequate health literacy [20]. We adapted the Hungarian NVS for online administration [45]. Instead of offering multiplechoice options in the online adaptation [46], we specified the measurement unit for answers in the questions and evaluated the accuracy of free-text answers.

\section{Minimum European Health Module}

We also inquired respondents' health by the Minimum European Health Module (MEHM). The MEHM consists of three questions. Self-perceived health evaluates current 
health on a 5-point Likert scale ("Very good"; "Good"; "Fair"; "Bad"; "Very Bad"). The Global Activity Limitation Indicator (GALI) asks limitations in activities over the past 6 months due to a health problem ("Not limited", "Limited but not severely", "Severely limited"). A final item (chronic morbidity) inquires the presence of long-standing health problems [6].

\section{Health-related information seeking and online behaviours}

Following the indirect measurement strategy of the European citizens' digital literacy survey [21], we included seven items to assess the frequency of various health-related information seeking and online behaviours over the past 12 months. Item 1 inquired about health information seeking in general and item 2 about participation at patient education programmes. Items 3-7 inquired about health-related use of the internet or mobile devices in different functional domains, motivated by the classification of the evidence standards framework of digital health interventions proposed by The National Institute for Health and Care Excellence (NICE) [17]. Item 3 inquired general online health-related administration, item 4 about online health-related information seeking, item 5 about online health-related communication with healthcare professionals, online helpers or peer patients, item 6 about online health prevention activities and item 7 about online disease management activities. All items were scored on a 6-point Likert scale ("Never", "Few times past year", "Bimonthly", "Monthly", "Several times per month", "At least once a week"). For hypothesis testing, we dichotomised each item to high and low activity at the median category.

\section{Demographic variables}

We recorded basic demographic variables age, gender, education, type of settlement, region and the place of residence based on postcode. Net monthly household income was queried in 11 range categories, and per-capita household income was calculated by dividing the category mid-range values by the number of household members, without adjustment for the number of children. The mid-range value of the upper open category was calculated by fitting the Pareto curve as proposed by Parker and Fenwick [47]. Local currency values were transformed to Euros using the average exchange rate for the period of Apr 1, 2019 Apr 1, $2020(€ 1=330.7$ HUF) [48].

\section{Lifestyle risk factors}

We recorded the most common modifiable risk factors for all-cause mortality and chronic conditions, such as BMI, smoking, alcohol intake, dietary habits, physical activity and sedentary behaviour [49-53]. Lifestyle risks were inquired via single-question self-reported items. In order to represent similar "severity levels", the following cut-off values were chosen that represent approximately 1.4-fold or greater relative risk increase for overall mortality: $\mathrm{BMI}<18.5$ or $\mathrm{BMI} \geq 30$ [54], current smoking [55, 56], sedentary behaviour $\geq 8 \mathrm{~h}$ per day with $<150$ min exercise per week or no exercise at all [57], no fruit and/or vegetable intake [58] and binge drinking $\geq 1$ day per week [59]. Binge drinking was defined as $>5$ drinks/occasion for men and $>4$ drinks/ occasion for women $[59,60]$. We also generated a lifestyle risk index by adding the number of lifestyle risk factors for each patient. Based on their lifestyle risk index, respondents were assigned to risk groups using stringent (no lifestyle risk vs any lifestyle risks) and relaxed (0-1 vs $2-4$ lifestyle risk factors) criteria.

\section{Preventive behaviours}

We considered as preventive behaviours the participation at screenings and vaccination programmes which are officially recommended in Hungary [61, 62]. According to this, for females, we counted the participation at cervical cancer screening between 25 and 65 years of age, breast cancer screening between 45 and 65 years of age, colorectal screening between 50 and 70 years of age, blood pressure, blood glucose and cholesterol levels measured within a year, flu vaccination at $60+$ years of age and bacterial pneumonia vaccination at $50+$ years of age. For males, we counted the participation at prostate and colorectal cancer screening between 50 and 70 years of age, blood pressure, blood glucose and cholesterol levels measured within a year, flu vaccination at $60+$ years of age and bacterial pneumonia vaccination at $50+$ years of age. To make respondents with different gender and age comparable, we calculated the preventive behaviour score as the proportion of performed preventive behaviours compared to the maximum of preventive behaviours prescribed for a given age and gender. For example, having only blood pressure measured within a year would represent a preventive behaviour score of 0.33 for a 40-year-old man (with only blood pressure, glucose and cholesterol check recommended), while it would be a score of 0.125 for a 60 -year-old woman, (for whom cervix, breast and colorectal cancer screenings, blood pressure, glucose and cholesterol tests as well as flu and bacterial pneumonia vaccinations are recommended). We also grouped respondents based on their preventive behaviour score $(<50 \%, \geq 50 \%)$.

\section{Excluded respondents}

Before data analysis, we checked the dataset for outliers and based on group consensus, set implausible values to missing or deleted entire records in case of potentially unreliable 
answer patterns. We deleted the data point if sedentary time was reported $>18 \mathrm{~h} /$ day. We deleted cases if the frequency of online health information seeking was reported over two categories greater than general health information seeking, response times shorter than $4 \mathrm{~s}$ per item for the survey instruments (PAM-13, eHEALS) or shorter than $1 \mathrm{~min}$ for the NVS instrument [63]. One respondent was excluded due to unlikely body parameters (height $111 \mathrm{~cm}$, weight $200 \mathrm{~kg}, \mathrm{BMI}=162$ ), and based on the PAM license owner's recommendation, we dropped individuals with a PAM-13 score of 0 and 100 (respondents who answer all strongly agree or all strongly disagree are likely not paying attention and responding in a valid way) as well as ones with not applicable answers in more than 3 PAM-13 items [64].

\section{Statistical methods}

We followed the applicable COSMIN guidelines for patientreported outcome measurement instruments when planning the methods of our study [65-67]. Missing data, descriptive statistics and distributional properties were assessed for all variables. The distribution of PAM-13 scores was assessed via inspection of the histogram and quantile plot, and normality was tested via the Shapiro-Wilk test. Floor and ceiling effects were assessed against the threshold of 15\% [68]. We tabulated respondents based on their PAM-13 levels. All analyses were performed on unweighted data.

\section{Reliability}

We evaluated internal consistency via computing Cronbach's alpha. Test-retest reliability for PAM-13 scores was assessed by intra-class correlation coefficient of agreement using a twoway random effects model $\left(\mathrm{ICC}_{\text {agreement }}\right.$ or ICC(A,1)) [69]. For categorical PAM-13 levels, we calculated weighted kappa using quadratic weights to progressively penalise greater differences between categories [69]. Measurement error (standard error of measurement, SEM) was calculated using the formula $\mathrm{SEM}=\sigma \times \sqrt{1-\mathrm{ICC}_{\text {agreement }}}$, where $\sigma$ is the pooled standard deviation of the sample from first and repeat administrations. The smallest detectable change (SDC, the smallest change that can be detected within a single person with $\mathrm{p}<0.05$ taking measurement error into consideration) was calculated via the following formula: $\mathrm{SDC}=1.96 \times \sqrt{2 \times \mathrm{SEM}}[38]$. We considered the following thresholds for good measurement properties: $\geq 0.7$ for $\mathrm{ICC}_{\text {agreement }}$ and weighted kappa, and the range of $0.7-0.95$ for Cronbach's alpha [38].

\section{Validity}

Content validity was assessed during the translation process; no further quantitative measurements were performed. Construct validity was assessed via confirmatory factor analysis using robust structural equitation modelling via the $\mathrm{R}$ package lavaan [70], assuming a single underlying factor. We checked the Kaiser-Meyer-Olkin (KMO) statistic for the adequacy of sampling [71] and Bartlett test for sphericity to check the adequacy of our data for factor analysis. Model fit was assessed by the RMSEA, the Tucker-Lewis index (TLI) and the comparative fit index (CFI), using cut-off values of $\leq 0.05,0.9$ and 0.9 for good fit, respectively. Convergent validity was assessed by the correlation between PAM-13 scores as well as PAM-13 levels and eHEALS scores, based on the assumption that both instruments measure advanced knowledge and are conceptually related to self-efficacy [19, 24]. We expected significant positive relationship between the two measures. Discriminant validity was tested by the expectation of weak or non-significant correlation between PAM-13 scores as well as PAM-13 levels and age, education and income, based on the assumption that PAM measures qualities that cannot be explained by socioeconomic status. We applied Pearson correlation between continuous measures, and polyserial correlation when categorical measures were involved.

When testing known-groups validity, our hypothesis was the following: patients practicing more preventive behaviours (preventive behaviour score $\geq 50 \%$ ), having fewer lifestyle risk factors according to the stringent (lifestyle risk index $=0$ ) or relaxed (lifestyle risk index $\leq 1$ ) criteria, those, who were more active in health information seeking, patient education, health-related communication, online/ mobile health information seeking, disease prevention or disease management activities had higher mean PAM-13 scores [24, 72]. We defined higher activity as having at least median scores on each item, or any activity over the past year, if majority of respondents did not engage in the respective online activity. The hypotheses were tested using onesided Welch's $t$ test. We also explored the same hypotheses in subgroups of patients with or without chronic disease, male or female respondents, respondents $\geq 65$ years of age or younger, respondents in the lowest income group or higher and respondents with adequate (NVS $\geq 4$ ) or lower health literacy scores. We deleted missing values pairwise for all statistical analyses. No missing values were imputed.

\section{Rasch analysis}

Insignia Health (copyright owner of PAM-13) provided the authors with PAM-13 scores based on the Rasch model [39, 73] as well as values of infit and outfit indices for each participant in both administrations of the survey. These indices 
measure the goodness-of-fit of the model to the observed response patterns. Infit is more sensitive to deviations on items aimed at the true activation levels of the respondents, whereas outfit is more sensitive to deviations on items aimed far from their true activation levels. Several thresholds for person infit and outfit indices exist in the literature, and according to one popular system [74], values below 0.3 imply a lack of expected variability in answers, values between 0.3 and 3.0 indicate good to high-quality data and values greater than 3 indicate unusual response patterns and thus poor-quality data $[75,76]$.

\section{Regression analysis}

We tested the association of PAM-13 score with the preventive behaviour score, lifestyle risk index, individual lifestyle-related risk factors (BMI, smoking, alcohol, physical activity and diet), health information seeking, participation at patient education and online health-related behaviours, when controlled for eHealth literacy (eHEALS), health literacy (NVS), age, gender, education, income, type of settlement and the health status of the respondent (MEHM items). We also replaced PAM-13 scores with PAM-13 levels. For continuous variables we applied OLS regression. Heteroskedasticity and model specification was tested via the Breusch-Pagan [77] and Ramsey RESET tests [78], respectively. In case of heteroskedasticity, we applied robust regression. Binary risk factors were analysed via logistic regression and the ordinal health information seeking and online behaviours via ordered logit models. For logistic and ordered logit models, goodness-of-fit was assessed via the binary and multinomial versions of the Hosmer-Lemeshow test $[79,80]$.

\section{Results}

\section{Descriptive statistics}

From the 900 survey respondents due to PAM-13-related quality issues, we excluded 92 respondents (10.2\%) and 29 respondents (3.2\%) for other reasons detailed above. Altogether $779(86.6 \%)$ individuals were included in our sample. In the repeat survey $(n=100)$, we excluded 11 respondents (11.0\%), who had PAM-13-related quality issues, 4 (4.0\%) due to other reasons and 10 respondents, who were excluded in the first administration. The retest sample comprised 75 respondents with had matching test-retest scores.

In the sample, mean age was $60.4(\mathrm{SD}=10.6)$ years, $54.0 \%$ were female and $66.5 \%$ reported to have chronic disease. Highly educated, affluent urban respondents were overrepresented compared to the $40+$ year-old general population (Table 1). The demographic characteristics of survey
Table 1 Sociodemographic characteristics and health status

\begin{tabular}{|c|c|c|c|c|c|}
\hline & \multicolumn{2}{|c|}{ Sample } & \multicolumn{2}{|c|}{$\begin{array}{l}\text { Retest } \\
\text { sample }\end{array}$} & \multirow{2}{*}{$\begin{array}{l}\text { General } \\
\text { population } \\
2011^{\mathrm{a}} \\
\%\end{array}$} \\
\hline & $n$ & $\%$ & $\%$ & $\%$ & \\
\hline Total & 779 & - & 75 & - & - \\
\hline \multicolumn{6}{|l|}{ Age group } \\
\hline $40-49$ & 143 & 18 & 14 & 15 & 26 \\
\hline $50-59$ & 177 & 23 & 14 & 21 & 28 \\
\hline $60-69$ & 306 & 39 & 11 & 37 & 23 \\
\hline $70+$ & 153 & 20 & 9 & 27 & 23 \\
\hline \multicolumn{6}{|l|}{ Gender } \\
\hline Male & 358 & 46 & 44 & 49 & 44 \\
\hline Female & 421 & 54 & 56 & 51 & 56 \\
\hline \multicolumn{6}{|l|}{ Education } \\
\hline Primary & 203 & 26 & 62 & 45 & 35 \\
\hline Secondary & 288 & 37 & 28 & 33 & 49 \\
\hline Tertiary & 288 & 37 & 10 & 21 & 16 \\
\hline \multicolumn{6}{|l|}{ Region } \\
\hline Central Hungary & 276 & 35 & 22 & 29 & 29 \\
\hline Central Transdanubia & 83 & 11 & 10 & 13 & 11 \\
\hline Western Transdanubia & 69 & 9 & 7 & 9 & 10 \\
\hline Southern Transdanubia & 89 & 11 & 9 & 12 & 10 \\
\hline Northern Hungary & 79 & 10 & 5 & 7 & 12 \\
\hline Northern Great Plain & 85 & 11 & 16 & 21 & 15 \\
\hline Southern Great Plain & 98 & 13 & 6 & 8 & 13 \\
\hline \multicolumn{6}{|l|}{ Type of settlement } \\
\hline Capital & 181 & 23 & 17 & 24 & 17 \\
\hline Town & 447 & 57 & 52 & 48 & 52 \\
\hline Village & 151 & 19 & 31 & 28 & 31 \\
\hline \multicolumn{6}{|l|}{ Income } \\
\hline 1st quintile & 75 & 11 & 20 & 12 & \\
\hline 2nd quintile & 106 & 16 & 20 & 20 & \\
\hline 3rd quintile & 74 & 11 & 20 & 13 & \\
\hline 4th quintile & 122 & 18 & 20 & 17 & \\
\hline 5th quintile & 291 & 44 & 20 & 38 & \\
\hline Missing & 111 & 14 & 6 & 8 & \\
\hline \multicolumn{6}{|l|}{ Self-rated health } \\
\hline Very good & 39 & 5 & 2 & 3 & \\
\hline Good & 267 & 34 & 25 & 33 & \\
\hline Fair & 397 & 51 & 39 & 52 & \\
\hline $\mathrm{Bad}$ & 66 & 8 & 8 & 11 & \\
\hline Very bad & 10 & 1 & 1 & 1 & \\
\hline Missing & 0 & 0 & 0 & 0 & \\
\hline \multicolumn{6}{|l|}{ Chronic morbidity } \\
\hline No & 253 & 33 & 20 & 27 & \\
\hline Yes & 503 & 67 & 54 & 73 & \\
\hline Missing & 23 & 3 & 1 & 1 & \\
\hline \multicolumn{6}{|l|}{ GALI } \\
\hline Not limited & 496 & 64 & 40 & 53 & \\
\hline Limited but not severely & 243 & 31 & 32 & 43 & \\
\hline Severely limited & 37 & 5 & 3 & 4 & \\
\hline
\end{tabular}


Table 1 (continued)

\begin{tabular}{|c|c|c|c|c|c|}
\hline & \multicolumn{2}{|c|}{ Sample } & \multicolumn{2}{|c|}{$\begin{array}{l}\text { Retest } \\
\text { sample }\end{array}$} & \multirow{2}{*}{$\begin{array}{l}\text { General } \\
\text { population } \\
2011^{\mathrm{a}} \\
\%\end{array}$} \\
\hline & $n$ & $\%$ & $\%$ & $\%$ & \\
\hline Missing & 3 & 0 & 0 & 0 & \\
\hline
\end{tabular}

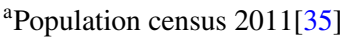

respondents and reasons for exclusion are summarised in Online Resource 2.

Mean $( \pm$ SD) PAM-13, eHEALS and NVS scores were $60.6( \pm 10.0), 28.7( \pm 5.1)$ and $3.9( \pm 1.7)$, respectively. The number (\%) of patients with PAM-13 levels $1,2,3$ and 4 were 54 (6.9\%), 169 (21.7\%), $471(60.5 \%)$ and 85 (10.9\%), respectively. Health literacy measured by the NVS was adequate $(\geq 4)$ for 491 (63.0\%), possibly limited (2-3) for $197(25.3 \%)$ and probably limited $(\leq 1)$ for $91(11.7 \%)$. Mean $( \pm \mathrm{SD})$ lifestyle risk index was $1.2( \pm 1.0)$. Out of 779 respondents $0,1,2$ and $\geq 3$ lifestyle risk factors were reported by $210(27.0 \%), 275(35.3 \%), 207(26.6 \%)$ and 87 $(11.2 \%)$, respectively. Mean $( \pm \mathrm{SD})$ preventive behaviour score was $0.45( \pm 0.25)$. According to the cut-off values for hypothesis testing, 466 (59.8\%) respondents searched healthrelated information at least monthly, $171(22.0 \%)$ participated in patient education over the past year, 443 (56.9\%) performed health-related administration over the internet, $421(54.0 \%)$ sought health-related information at least bimonthly, 196 (25.2\%) communicated online over past year about health with healthcare professionals, helpers or peers, $280(35.9 \%)$ engaged in online health prevention activities and 347 (44.5\%) participated in online disease management activities over the past year (Online Resource 3).

\section{Classic test theory methods}

The distribution plots of PAM-13 are displayed in Online Resource 4. We summarised the psychometric properties of PAM-13 along with the applied methods, target values and results in Table 2. Altogether, PAM-13 scores fit rather log-normal than normal distribution with no floor or ceiling effect. Internal consistency was adequate, while test-retest reliability was moderate. The single-factor structure was confirmed, convergent validity (correlation with eHEALS scores) and discriminant validity hypotheses (low/no correlation with age, education and income) were supported. Known-groups validity tests were significant in 7/9 (77.8\%) hypotheses.

The results of known-groups hypothesis tests in various subgroups are summarised in Online Resource 5. Generally fewer than 7 hypotheses were supported in the subgroups than in the entire sample, except for participants with chronic morbidity ( $n=503,7 / 9$ hypothesis supported) and 40-65 years old ( $n=483,8 / 9$ hypothesis supported). None of the hypotheses were supported in the $>65$ age group $(n=296)$. Respondents with higher PAM-13 levels had fewer lifestyle risk factors in $9 / 10$ subgroups and sought more often health information in 7/10 subgroups. The smallest detectable change (SDC) was 7.1 points.

\section{Rasch analysis}

Table 3 summarises the data quality of the Rasch model based on the person infit and outfit indices. The results indicate that the PAM-13 scores used in this paper are based on high-quality, consistent data.

\section{Regression analysis}

When controlled for eHealth literacy, health literacy, sociodemographic variables and respondents' health status, the association of PAM-13 scores with lifestyle-related risks remained significant. In particular, higher PAM-13 scores were associated with fewer lifestyle-related risks overall, lower probability of risky BMI ( $<18.5$ or $>30)$, physical inactivity or diet low in fruits and/or vegetables. However, smoking and binge drinking episodes were not associated with PAM-13. Furthermore, although health information seeking, participation at patient education programmes and several online health-related behaviours were associated with PAM in bivariate hypothesis tests, in multiple regression models these factors were associated with eHEALS or NVS but not with PAM-13 scores. Higher preventive behaviour scores were associated with higher education levels, but neither with patient activation (PAM-13 score or level) nor with health literacy (eHEALS or NVS). The regression table is shown in Online Resource 6.

PAM-13 levels showed similar pattern to PAM scores (Online Resource 6). After controlling for the regression predictor variables, the adjusted probabilities of various lifestyle-related risks at different PAM-13 levels are depicted in Fig. 1 for the entire sample, in Fig. 2 for the subgroup with chronic morbidity and in Fig. 3 for 65+ year-old patients. While the pattern of participants with chronic morbidity was similar to the entire sample, neither the overall number of risk factors nor the level of physical activity was associated with higher PAM-13 levels in the elderly $(65+)$ subgroup (Online Resources 8, 9 and 10).

\section{Discussion}

In this cross-sectional online survey among the 40+ year-old Hungarian general population, we demonstrated the validity and tested the psychometric properties of the Hungarian 
Table 2 Summary of the results of classical test theory methods

\begin{tabular}{|c|c|c|c|c|c|c|}
\hline Category & Property & Method & Target & Result & $p$ value/[95\% CI $]$ & Comment \\
\hline \multirow[t]{6}{*}{ General } & \multirow[t]{6}{*}{ Distribution } & Skewness & 0.00 & 0.36 & $<0.001$ & Positive skew \\
\hline & & Kurtosis & 3.00 & 3.24 & 0.165 & Normal kurtosis \\
\hline & & Shapiro-Wilk test for normal distribution & $p \geq 0.05$ & - & $<0.001$ & Deviation from normality \\
\hline & & $\begin{array}{l}\text { Shapiro-Wilk test for log-normal distribu- } \\
\text { tion }\end{array}$ & $p \geq 0.05$ & - & 0.811 & Log-normal distribution \\
\hline & & Floor effect & $<15 \%$ & $0.13 \%$ & {$[0.0-0.7 \%]$} & No floor effect \\
\hline & & Ceiling effect & $<15 \%$ & $0.25 \%$ & {$[0.0-0.9 \%]$} & No ceiling effect \\
\hline \multirow[t]{5}{*}{ Reliability } & Internal consistency & Cronbach alpha & $0.7-0.95$ & 0.77 & {$[0.74-0.79]$} & Adequate \\
\hline & \multirow[t]{4}{*}{ Test-retest reliability } & $\mathrm{ICC}_{\text {agreement }}{ }^{\mathrm{a}}$ & $>0.7$ & 0.62 & {$[0.46-0.74]$} & Moderate \\
\hline & & Standard error of measurement & - & 6.5 & {$[5.4-7.8]$} & - \\
\hline & & Smallest detectable change & - & 7.1 & {$[6.4-7.7]$} & - \\
\hline & & Weighted kappa ${ }^{\mathrm{b}}$ & $>0.7$ & 0.46 & {$[0.26-0.65]$} & Moderate \\
\hline \multirow[t]{19}{*}{ Validity } & \multirow[t]{5}{*}{ Structural validity $\left(\mathrm{CFA}^{\mathrm{c}}\right)$} & Sample: $\mathrm{KMO}^{\mathrm{d}}$ & 0.5 & 0.84 & - & Adequate \\
\hline & & Sample: Bartlett test & $p<0.05$ & - & $<0.0001$ & \\
\hline & & Single factor: RMSEA ${ }^{\mathrm{e}}$ & $<0.05$ & 0.049 & [0.041-0.057] & Good fit \\
\hline & & Single factor: $\mathrm{CFI}^{\mathrm{f}}$ & $>0.90$ & 0.947 & - & \\
\hline & & Single factor: $\mathrm{TLI}^{\mathrm{g}}$ & $>0.90$ & 0.937 & - & \\
\hline & \multirow[t]{2}{*}{ Convergent validity } & PAM-13-eHEALS ${ }^{\mathrm{h}}$ Pearson correlation & $r>0.3^{\mathrm{i}}$ & $r=0.40$ & $<0.001$ & Supported \\
\hline & & $\begin{array}{l}\text { PAM-13 levels-eHEALS } \\
\text { Polyserial correlation }^{\text {b }}\end{array}$ & $\rho>0.3^{\mathrm{i}}$ & $\rho=0.39$ & $<0.001$ & Supported \\
\hline & \multirow[t]{3}{*}{ Discriminant validity } & $\begin{array}{l}\text { PAM-13 - age } \\
\text { Pearson correlation }\end{array}$ & $r<0.3^{\mathrm{j}}$ & $r=0.02$ & 0.524 & Supported \\
\hline & & $\begin{array}{l}\text { PAM-13-education } \\
\text { polyserial correlation }\end{array}$ & $\rho<0.3^{\mathrm{j}}$ & $\rho=0.04$ & 0.273 & Supported \\
\hline & & $\begin{array}{l}\text { PAM-13-income quintiles } \\
\text { polyserial correlation }\end{array}$ & $\rho<0.3^{\mathrm{j}}$ & $\rho=0.04$ & 0.321 & Supported \\
\hline & \multirow{9}{*}{$\begin{array}{l}\text { Known-groups validity } \\
\text { (PAM-13 score difference) }\end{array}$} & $\mathrm{PBS}^{\mathrm{k}} \geq 50 \%$ vs $\mathrm{PBS}<50 \%$ & $\Delta>0.0^{\mathrm{i}}$ & $\Delta=0.91$ & 0.102 & Not supported \\
\hline & & Lifestyle risk index:0 vs $\geq 1$ & $\Delta>0.0^{\mathrm{i}}$ & $\Delta=3.87$ & $<0.001$ & Supported \\
\hline & & Lifestyle risk index $\leq 1$ vs $\geq 2$ & $\Delta>0.0^{\mathrm{i}}$ & $\Delta=4.47$ & $<0.001$ & Supported \\
\hline & & $\begin{array}{l}\text { Health information seeking at least } \\
\text { monthly vs less }\end{array}$ & $\Delta>0.0^{\mathrm{i}}$ & $\Delta=2.41$ & $<0.001$ & Supported \\
\hline & & Patient education over past year vs none & $\Delta>0.0^{\mathrm{i}}$ & $\Delta=1.88$ & 0.018 & Supported \\
\hline & & $\begin{array}{l}\text { Online health information seeking at least } \\
\text { bimonthly or less }\end{array}$ & $\Delta>0.0^{\mathrm{i}}$ & $\Delta=0.91$ & 0.104 & Not supported \\
\hline & & $\begin{array}{l}\text { Online health-related communication past } \\
\text { year vs none }\end{array}$ & $\Delta>0.0^{\mathrm{i}}$ & $\Delta=1.61$ & 0.025 & Supported \\
\hline & & $\begin{array}{l}\text { Online health-prevention over past year } \\
\text { vs none }\end{array}$ & $\Delta>0.0^{\mathrm{i}}$ & $\Delta=1.60$ & 0.015 & Supported \\
\hline & & $\begin{array}{l}\text { Online disease management over past year } \\
\text { vs none }\end{array}$ & $\Delta>0.0^{\mathrm{i}}$ & $\Delta=1.46$ & 0.044 & Supported \\
\hline
\end{tabular}

${ }^{\mathrm{a}} \mathrm{ICC}$ : intra-class coefficient

${ }^{b}$ Results refer to PAM-13 levels (all other results: PAM scores)

${ }^{\mathrm{c}} \mathrm{CFA}$ : confirmatory factor analysis

${ }^{\mathrm{d}}$ KMO: Kaiser-Meyer-Olkin statistic

${ }^{\mathrm{e}} \mathrm{RMSEA}$ : root mean squared error of approximation

${ }^{\mathrm{f}} \mathrm{CFI}$ : comparative fit index

gTLI: Tucker-Lewis Index

heHEALS: eHealth Literacy Scale

${ }^{\mathrm{i}} p<0.05$, significant

${ }^{\mathrm{j}} p \geq 0.05$, not significant

${ }^{k}$ PBS: preventive behaviour score 
Table 3 Summary of Rasch data quality indices

\begin{tabular}{llllll}
\hline & \multicolumn{2}{l}{ First administration } & & \multicolumn{2}{l}{ Second administration } \\
\cline { 2 - 3 } \cline { 5 - 6 } & Good to high & Poor & & Good to high & Poor \\
\hline Infit & $732(94.0 \%)$ & $47(6.0 \%)$ & & $72(96.4 \%)$ & $3(3.6 \%)$ \\
Outfit & $728(93.5 \%)$ & $51(6.5 \%)$ & & $72(96.4 \%)$ & $3(3.6 \%)$ \\
\hline
\end{tabular}

version of the PAM-13 instrument. Following the COSMIN guidelines, we found good internal consistency, moderate test-retest reliability, a single-factor structure and good content validity consistent with majority of the predefined hypotheses. In particular, higher PAM-13 scores of PAM-13 levels were associated with fewer lifestyle-related risks even
Fig. 1 Adjusted probability of lifestyle-related risks at various PAM-13 levels in the entire sample. $P B S$ preventive behaviour score, $L R I$ lifestyle risk index, $B M I$ body mass index
Fig. 2 Adjusted probability of lifestyle-related risks at various PAM-13 levels in the subgroup with chronic morbidity. $P B S$ preventive behaviour score, $L R I$ lifestyle risk index, $B M I$ body mass index

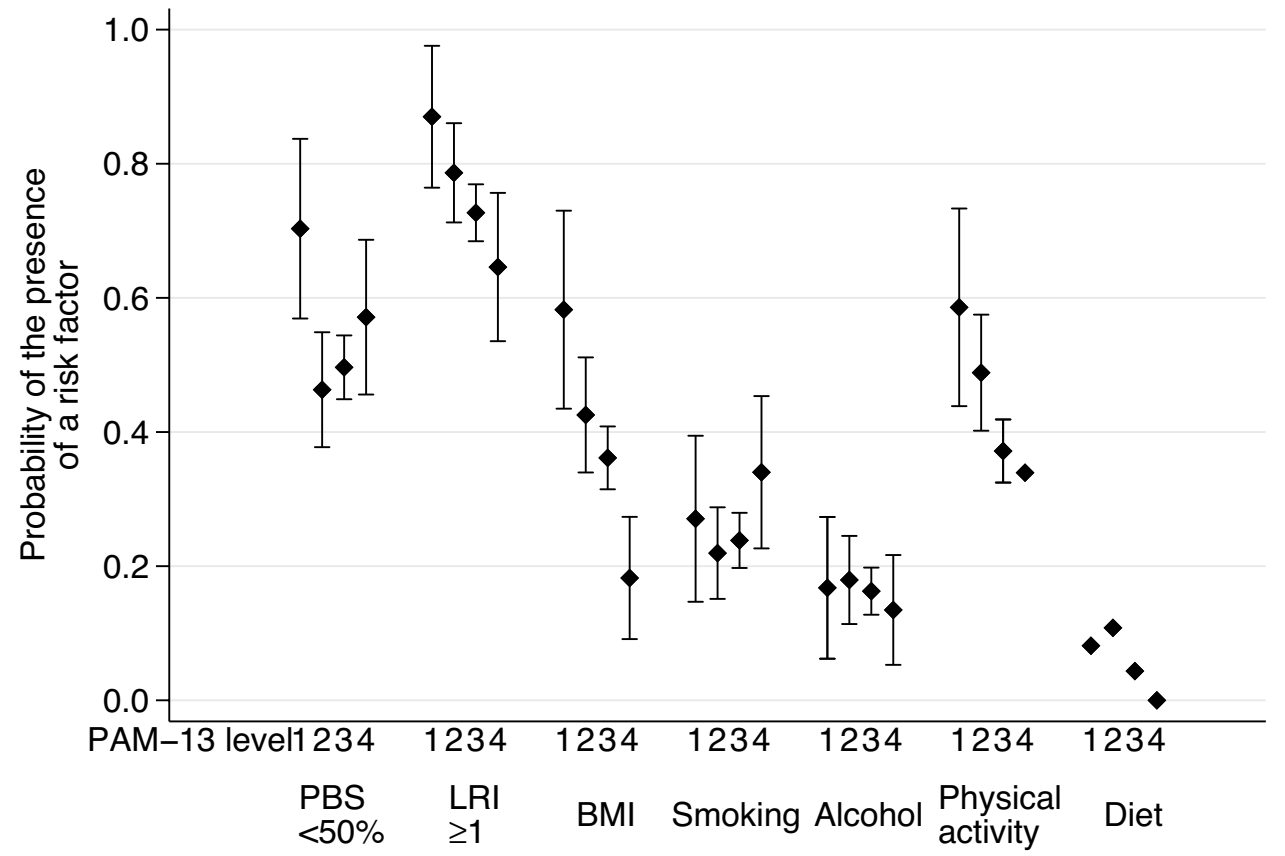

Missing confidence intervals are not estimable due to the presence of perfect predictors

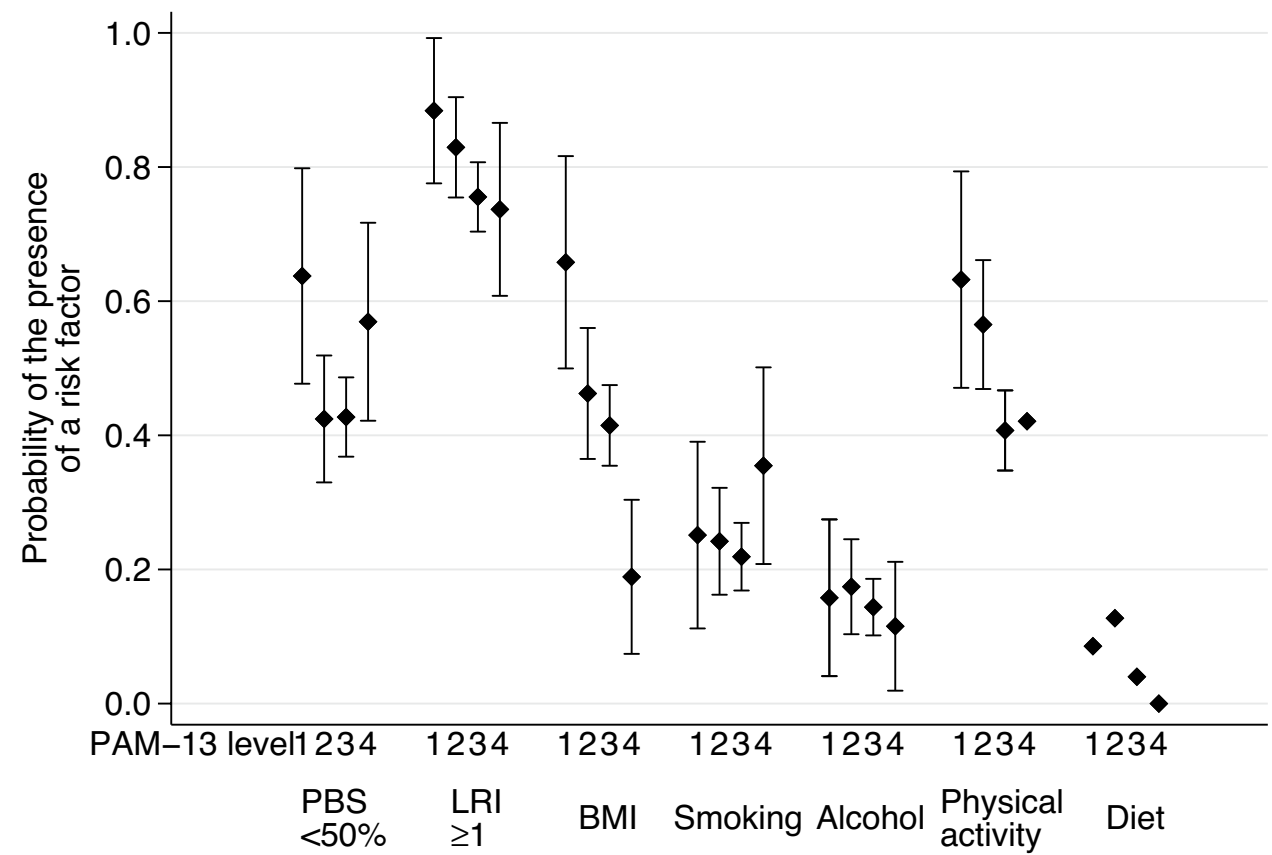

Missing confidence intervals are not estimable due to the presence of perfect predictors 
Fig. 3 Adjusted probability of lifestyle-related risks at various PAM-13 levels in the $65+$ subgroup. $P B S$ preventive behaviour score, $L R I$ lifestyle risk index, $B M I$ body mass index

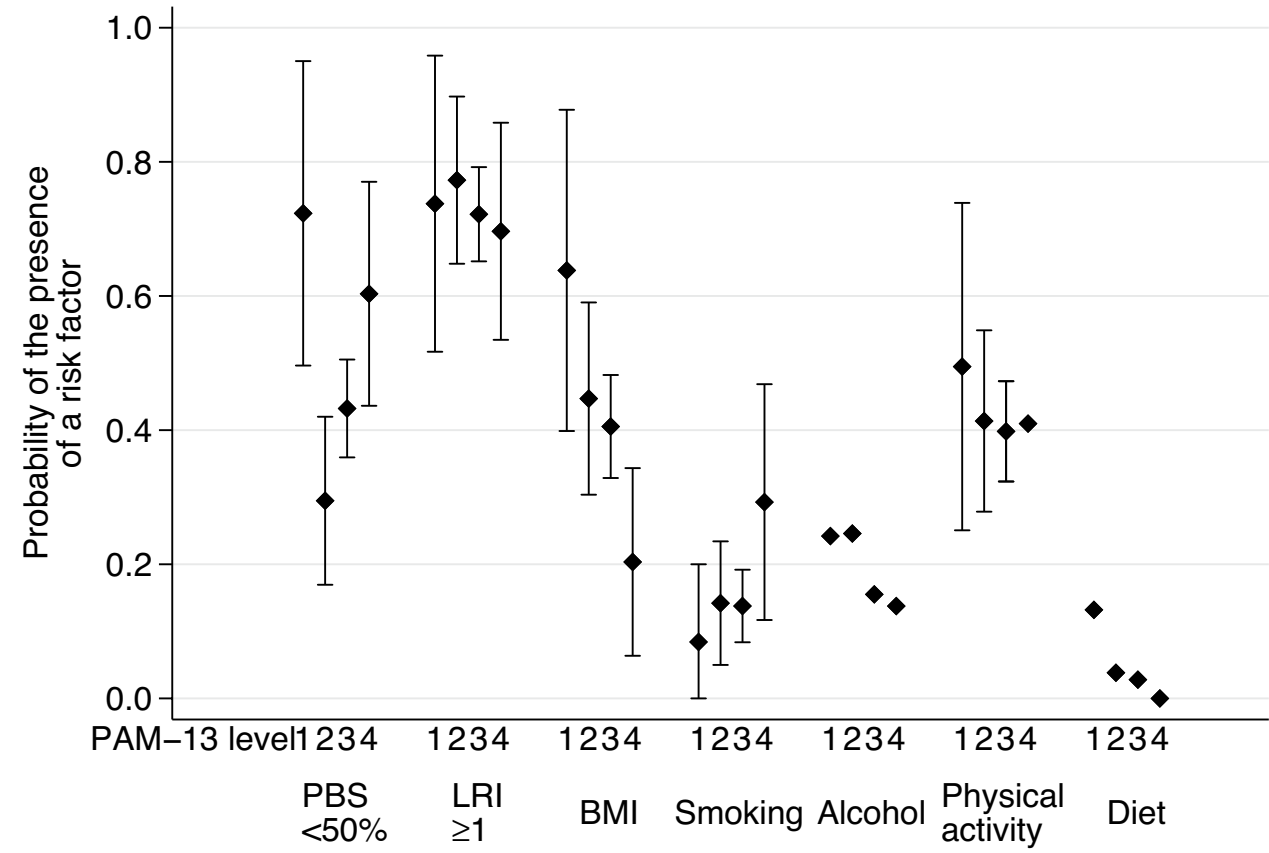

Missing confidence intervals are not estimable due to the presence of perfect predictors when controlled for eHealth literacy, health literacy, socioeconomic characteristics and the health status of respondents. Higher PAM-13 scores were especially associated with greater probability of having normal BMI, being physically active and having a diet, including vegetables and fruits. However, smoking and risky alcohol intake were not associated with PAM-13 scores.

The results of bivariate hypothesis tests were consistent with the entire sample in the subgroup of respondents with self-reported chronic morbidity and in the 40-65 years old age group. However, in the 65+ population higher PAM-13 levels were not associated with either fewer lifestyle risk factors or more health information seeking, participation at patient education or online health-related activities. Albeit not significant, the pattern of regression coefficients of lifestyle risk factors, BMI, physical activity and diet on PAM-13 score in the $65+$ age group were similar to those in the general population (Online Resource 10). Therefore, the validity of PAM-13 in the elderly population should be further studied with larger population samples and confirmed by testing alternative hypotheses more relevant to this population, such as disease management, medication adherence [29] or costs of care [40].

Our results are consistent with other validation studies. Comparisons are more relevant with surveys that were conducted among the general population; however, the differences between the demographic characteristics of the samples should be considered. The PAM instruments were developed on a sample of $45+$ year-old individuals from the US general population, with $34 \%$ over age of 65
$[24,39]$. Fowles et al. assessed the validity of PAM-13 in a younger age group: US employees with mean age 45 of years [81]. PAM-13 was also validated in the general population of Israel (age 65+: 26.7\%) [82] and the Netherlands (age 65+: 29.3\%) [83]. The average PAM-13 score varied between 60.2 and 70.7 across the four studies, our result was closest to the original development study (60.6 vs. 60.2) [39]. Cronbach alpha varied between 0.77 and 0.9 [24, 39, 82, 83]. Associations between PAM-13 and demographic characteristics (age, gender, educational level) varied across the four studies; however, positive association with health status (assessed by different measurement tools) was rather consistent [24, 39, 82, 83].

We tested the association between patient activation and a broad set of variables concerning participants' healthrelated risk factors, information seeking and health management behaviour. Similarly to our findings, Hibbard et al. reported that the preventive, consumeristic and the disease-specific self-management behaviours were strongly associated with PAM-13 scores [39]. Fowles et al. found strong positive association between PAM-13 and personal healthy behaviours and health information seeking [81]. While online health information seeking was not associated with PAM-13 scores in our entire sample, in younger individuals and ones without chronic disease the association was positive. Health information seeking in general was not associated with PAM-13 scores in the elderly. As shown by our regression analyses and suggested by previous research, patient activation is rather 
associated with health behaviours, while information seeking is rather associated with health literacy [25].

The aim of PAM-13 is to measure skills, knowledge and motivation necessary for patients' effective contribution to their own care, and eventually predict better outcomes [24, 39]. In our study, the items of MEHM were used to control for the health status of respondents. However, assuming diverse health-related behaviours and health states in the general population, the association between PAM-13 and health status was not tested in this study.

PAM-13 validation studies were conducted also in a series of specific patient populations, including diabetes [37, 84, 85], metabolic syndrome [86], multiple sclerosis [87], neurological disorders [88, 89], hypertension [37, 85], cardiac conditions [90], schizophrenia [91], mental disorders [92], osteoarthritis [93-95], rheumatic diseases [37, 96], HIV [97] or not specified chronic diseases [98-100], and clinical settings in different countries [101-105]. In some of these studies, convergent validity was assessed using generic and disease-specific measures of health-related attitudes or behaviours, such as self-efficacy [87, 88, 96, 101], selfesteem [98], lifestyle [89] or health literacy [103, 106]. For the assessment of convergent validity, we chose the eHEALS scale, a widely used measure of self-reported eHealth literacy that is strongly rooted in self-efficacy theory [19, 42]. While PAM-13 and eHEALS showed moderate positive correlation, the multiple regression analyses revealed that the two instruments are associated with different facets of health-related behaviours. While higher PAM-13 scores predicted healthier lifestyles, higher eHEALS scores were associated with more frequent health information seeking and online health-related behaviours.

The strength of our study is that it met the most meticulous methodological standards outlined by the COSMIN best practices guide [65]: all phases of our approach, including descriptions of the research aim, the PROM and the target population, the design requirements, the analysis of structural validity, internal consistency, measurement invariance, measurement error and reliability, criterion validity, construct validity, known-groups validity and the construct approach (hypothesis testing), fell into the highest quality category defined by these guidelines.

We note that 92 out of 900 respondents $(10.2 \%)$ were excluded from the survey due to PAM-13-related quality issues, following the developers' recommendations [64]. While more than three "not applicable" responses $(N=51$, $5.6 \%$ ) may indicate that a respondent lacks relevant healthrelated experiences, "straightlining" patterns (e.g. all "disagree strongly" or "agree strongly" on all items, $N=41,4.6 \%$ ) are potential indicators of meaningless responses, especially given the Guttman scale-like structure of PAM-13, which involves items with increasing difficulty levels to reflect the developmental model of patient activation [24, 64] Due to other potential indicators of low data quality, such as low response times or grossly inconsistent patterns, we excluded respondents sparingly $(N=29,3.2 \%)$ to decrease measurement error, while avoiding interference with results [107].

The limitation of our study is that PAM-13 was administered in an online general population, with over-representation of highly educated, affluent urban respondents, which reflects the general sampling bias of online surveys [108]. However, patients from rural regions or lower socioeconomic status may be particularly prone to lifestyle risks and poor health status $[109,110]$; therefore, the validity of the patient activation concept is of particular importance in these populations. Nevertheless, in subgroups with the lowest income and inadequate health literacy levels, higher PAM-13 scores were associated with fewer lifestyle risk factors and more frequent health information seeking in our study, which supports the validity of the PAM-13 instrument in these vulnerable subgroups. Furthermore, although the validity of PAM-13 was supported among respondents with self-reported chronic morbidity, further studies are required to assess the psychometric properties of PAM in clinical settings also including younger adults. While we assumed low applicability for many PAM-13 items in the general population below 40 years of age, clinical validation studies of PAM-13 should involve a wider spectrum of ages.

Furthermore, as a potentially modifiable enhancer of patients' contribution to the health production process, the responsiveness of PAM-13 to interventions is of key interest $[4,111]$. However, the responsiveness of PAM-13 is a poorly explored area. We found one validation study from Norway in which patients with chronic inflammatory arthritis attending a patient education programme were involved [96]. The low responsiveness was partly explained by the substantial ceiling effect in 10 of the 13 items. Our results suggest that the moderate test-retest reliability of PAM-13 necessitates sufficiently large sample sizes in adequately powered studies to demonstrate change. We encourage further research both among the general public and patient populations to get a better insight into responsiveness of PAM-13 to interventions.

We suppose that certain properties of PAM-13 may be context specific depending on the healthcare setting. In Hungary, the weak primary care system acts as a gatekeeper and offers limited choice of providers [112], while healthcare remains hospital centric and inefficient despite the low expenditure levels [113]. Therefore, while patient activation may be associated with more efficient use of healthcare resources [40], activated patients may also cost more by demanding more services. For example, Hungarian patients from low socioeconomic status may have poorer overall access to care [110]. High activation may contribute to lower utilisation of costly emergency care and increase the utilisation of routine care in this 
population. Altogether, while higher PAM-13 scores were associated with lower resource use in the US healthcare system $[28,30]$, the association of PAM-13 with costs of care warrants further research in the Hungarian context.

As a conclusion, the Hungarian version of the PAM-13 demonstrated good validity in the 40-65-year-old general population as well as among people with self-reported chronic morbidity. Further research is needed to establish the validity of PAM-13 in clinical populations as well as among the elderly and its responsiveness to interventions.

Supplementary Information The online version contains supplementary material available at https://doi.org/10.1007/s10198-022-01434-0.

Author contributions All the authors contributed to the study conception and design. Linguistic adaptation was performed by ÁD and ZZ. Material preparation, data collection and analysis were performed by ZZ, MP, LG and LK. Formal analysis was performed by ZZ, PV, PN, $\mathrm{OH}$ and $\mathrm{JH}$. The first draft of the manuscript was written by ZZ, PV and MP. All the authors commented on previous versions of the manuscript. All the authors read and approved the final manuscript.

Funding Open access funding provided by Óbuda University. This research has been implemented under Project No. TKP2020-NKA-02 with the support provided from the National Research, Development and Innovation Fund of Hungary, financed under the Tématerületi Kiválósági Program funding scheme.

Availability of data and material Data are available upon reasonable request from the authors.

Code availability The code of statistical analyses is available upon reasonable request from the authors.

\section{Declarations}

Conflict of interest Financial interests: In connection with writing the manuscript, ZZ, PV, PN, ÁD, OH, LG and MP have received financial support from project no. TKP2020-NKA-02 of the National Research, Development and Innovation Fund of Hungary, financed under the Tématerületi Kiválósági Program funding scheme at Corvinus University of Budapest. During writing this article, $\mathrm{ZZ}$ has received funding from the European Research Council (ERC) under the European Union's Horizon 2020 research and innovation programme (grant agreement No 679681). MP has received funding from Project no. 2019-1.3.1KK-2019-00007 implemented with the support provided from the National Research, Development and Innovation Fund of Hungary, financed under the 2019-1.3.1-KK funding scheme. PV has received funding from the National Research, Development and Innovation Office (FK-132343) Health Economics Research Center. Non-financial interests: MP is member of the EuroQol Group, a not-for-profit organisation that develops and distributes instruments that assess and value health. KNIA has no relevant financial or non-financial interests to disclose.

Ethics approval This study was approved by the Ethical Committee of the Medical Research Council of Hungary (ETT TUKEB, ID: 497023/2019/EKU).

Consent to participate All participants were informed and provided their consent prior to completing the survey.
Consent for publication All the authors have approved the final manuscript and consent for publication.

Open Access This article is licensed under a Creative Commons Attribution 4.0 International License, which permits use, sharing, adaptation, distribution and reproduction in any medium or format, as long as you give appropriate credit to the original author(s) and the source, provide a link to the Creative Commons licence, and indicate if changes were made. The images or other third party material in this article are included in the article's Creative Commons licence, unless indicated otherwise in a credit line to the material. If material is not included in the article's Creative Commons licence and your intended use is not permitted by statutory regulation or exceeds the permitted use, you will need to obtain permission directly from the copyright holder. To view a copy of this licence, visit http://creativecommons.org/licenses/by/4.0/.

\section{References}

1. WHO.: Chronic diseases and health promotion (2019). https:// www.who.int/chp/about/integrated_cd/en/

2. OECD.: Fiscal Sustainability of Health Systems: Bridging Health and Finance Perspectives. OECD Publishing, Paris (2015)

3. Institute of Medicine.: Crossing the quality chasm: a new Health System for the 21 century, Washington, DC (2005)

4. World Health Organization: WHO global strategy on peoplecentred and integrated health services - Interim report. WHO, Geneva (2015)

5. Berwick, D., et al.: Recommendations to OECD Ministers of Health from the High Level Reflection Group on the future of health statistics: strengthening the international comparison of health system performance through patient-reported indicators. OECD, Paris (2017)

6. Cox, B., et al.: The reliability of the Minimum European Health Module. Int. J. Public Health 54(2), 55-60 (2009)

7. Eurostat.: Glossary: minimum European health module (MEHM) (2019). https://ec.europa.eu/eurostat/statistics-explained/index. php/Glossary:Minimum_European_Health_Module_(MEHM)

8. WHO.: Action plan for the prevention and control of noncommunicable diseases in the WHO European Region. WHO Regional Office for Europe, Copenhagen (2016)

9. WHO.: Healthy, prosperous lives for all: the European Health Equity Status Report. World Health Organization Regional Office for Europe, Copenhagen (2019)

10. Bircher, J., Kuruvilla, S.: Defining health by addressing individual, social, and environmental determinants: new opportunities for health care and public health. J. Public Health Policy 35(3), 363-386 (2014)

11. Wallston, K.A., Wallston, B.S., DeVellis, R.: Development of the Multidimensional Health Locus of Control (MHLC) Scales. Health Educ. Monogr. 6(2), 160-170 (1978)

12. Bandura, A.: Self-efficacy: toward a unifying theory of behavioral change. Psychol. Rev. 84(2), 191-215 (1977)

13. Lorig, K.: Self-management of chronic illness: a model for the future. Generations 17(3), 11-14 (1993)

14. Prochaska, J., Redding, C., Evers, K.: The transtheorethical model model and stages of change. In: Glanz, K., Rimer, B., Viswanath, K. (eds.) Health Behaviour and Health Education Theory, Research and Practice, 4th edn. Jossey-Bass, San Francisco (2008)

15. Coleman, K., et al.: Evidence on the Chronic Care Model in the new millennium. Health Aff. (Millwood) 28(1), 75-85 (2009) 
16. Morton, K., et al.: Using digital interventions for self-management of chronic physical health conditions: a meta-ethnography review of published studies. Patient Educ. Couns. 100(4), 616635 (2017)

17. NICE.: Evidence standards framework for digital health technologies. London (2019)

18. Santana, S., et al.: updating health literacy for healthy people 2030: defining its importance for a new decade in public health. J. Public Health Manag. Pract. 27(Suppl 6), S258-S264 (2021)

19. Norman, C.D., Skinner, H.A.: eHEALS: the eHealth Literacy Scale. J. Med. Internet Res. 8(4), e27 (2006)

20. Weiss, B.D., et al.: Quick assessment of literacy in primary care: the newest vital sign. Ann. Fam. Med. 3(6), 514-522 (2005)

21. TNS.: European Citizen's Digital Health Literacy. In: Flash Eurobarometer 404, Luxembourg (2014)

22. Neter, E., Brainin, E.: Association between health literacy, eHealth literacy, and health outcomes among patients with long-term conditions. Eur. Psychol. 24(1), 68-81 (2019)

23. Han, H.R., et al.: eHealth literacy in people living with HIV: systematic review. JMIR Public Health Surveill. 4(3), e64 (2018)

24. Hibbard, J.H., et al.: Development of the patient activation measure (PAM): conceptualizing and measuring activation in patients and consumers. Health Serv. Res. 39(4 Pt 1), 1005-1026 (2004)

25. Hibbard, J.: Patient activation and health literacy: what's the difference? How do each contribute to health outcomes. Stud. Health Technol. Inform. 240, 251-262 (2017)

26. Insignia Health.: The Science of the PAM survey (2019). https:// www.insigniahealth.com/research/science

27. Mosen, D., et al.: Is patient activation associated with outcomes of care for adults with chronic conditions? J. Ambul. Care Manage. 30(1), 21-29 (2007)

28. Harvey, L., et al.: When activation changes, what else changes? The relationship between change in patient activation measure (PAM) and employees' health status and health behaviors. Patient Educ. Couns. 88(2), 338-343 (2012)

29. Graffigna, G., Barello, S., Bonanomi, A.: The role of Patient Health Engagement Model (PHE-model) in affecting patient activation and medication adherence: a structural equation model. PLoS ONE 12(6), e0179865 (2017)

30. Remmers, C., et al.: Is patient activation associated with future health outcomes and healthcare utilization among patients with diabetes? J. Ambul. Care Manag. 32(4), 320-327 (2009)

31. Aziz, A., Reynolds, R., Ansari, A.: Process and systems: a population-based model of care for people with inflammatory bowel disease-patient-reported outcomes. Future Healthc. J. 6(1), 30-35 (2019)

32. Schnock, K.O., et al.: Acute care patient portal intervention: portal use and patient activation. J. Med. Internet Res. 21(7), e13336 (2019)

33. Carroll, J.K., et al.: "Get Ready and Empowered About Treatment" (GREAT) Study: a pragmatic randomized controlled trial of activation in persons living with HIV. J. Gen. Intern. Med. 34(9), 1782-1789 (2019)

34. Korm.: határozat az „Egészséges Magyarország 2014-2020” Egészségügyi Ágazati Stratégia 2017-2018 évekre vonatkozó cselekvési tervérôl, in 1886/2016. (XII. 28.), Egészségügyi Közlöny LXVI. évfolyam 1, Hungary (2017)

35. KSH.: Population census 2011. Hungarian Central Statistical Office: Online (2011)

36. Skolasky, R.L., et al.: Psychometric properties of the patient activation measure among individuals presenting for elective lumbar spine surgery. Qual. Life Res. 18(10), 1357-1366 (2009)

37. Kosar, C., Besen, D.B.: Adaptation of a patient activation measure (PAM) into Turkish: reliability and validity test. Afr. Health Sci. 19(1), 1811-1820 (2019)
38. Terwee, C.B., et al.: Quality criteria were proposed for measurement properties of health status questionnaires. J. Clin. Epidemiol. 60(1), 34-42 (2007)

39. Hibbard, J.H., et al.: Development and testing of a short form of the patient activation measure. Health Serv. Res. 40(6 Pt 1), 1918-1930 (2005)

40. Lindsay, A., et al.: Patient activation changes as a potential signal for changes in health care costs: cohort study of US high-cost patients. J. Gen. Intern. Med. 33(12), 2106-2112 (2018)

41. WHO.: Process of translation and adaptation of instruments (2019). https://www.who.int/substance_abuse/research_tools/ translation/en/

42. Zrubka, Z., et al.: Psychometric properties of the Hungarian version of the eHealth Literacy Scale. Eur. J. Health Econ. 20(Suppl 1), 57-69 (2019)

43. van der Vaart, R., et al.: Does the eHealth Literacy Scale (eHEALS) measure what it intends to measure? Validation of a Dutch version of the eHEALS in two adult populations. J. Med Internet Res. 13(4), e86 (2011)

44. Neter, E., Brainin, E.: Perceived and performed eHealth literacy: survey and simulated performance test. JMIR Hum. Factors 4(1), e2 (2017)

45. Koltai, J., Kun, E.: The practical measurement of health literacy in Hungary and in international comparison. Orv. Hetil. 157(50), 2002-2006 (2016)

46. Mansfield, E.D., et al.: Canadian adaptation of the Newest Vital Sign(c), a health literacy assessment tool. Public Health Nutr. 21(11), 2038-2045 (2018)

47. Parker, R.N., Fenwick, R.: The Pareto curve and its utility for open-ended income distributions in survey research. Soc. Forces 61(3), 872-885 (1983)

48. European Central Bank Eurosystem.: Euro foreign exchange reference rates (2020). https://www.ecb.europa.eu/stats/policy_ and_exchange_rates/euro_reference_exchange_rates/html/ eurofxref-graph-huf.en.html

49. Stein, C.J., Colditz, G.A.: Modifiable risk factors for cancer. Br. J. Cancer 90(2), 299-303 (2004)

50. Lim, S.S., et al.: Validation of a new predictive risk model: measuring the impact of the major modifiable risks of death for patients and populations. Popul. Health Metr. 13, 27 (2015)

51. $\mathrm{Ng}$, R., et al.: Smoking, drinking, diet and physical activitymodifiable lifestyle risk factors and their associations with age to first chronic disease. Int. J. Epidemiol. 49(1), 113-130 (2020)

52. WHO.: Global Status Report About Noncommunicable Diseases. WHO, Geneva (2014)

53. McGorrian, C., et al.: Estimating modifiable coronary heart disease risk in multiple regions of the world: the INTERHEART Modifiable Risk Score. Eur. Heart J. 32(5), 581-589 (2011)

54. Di Angelantonio, E., et al.: Body-mass index and all-cause mortality: individual-participant-data meta-analysis of 239 prospective studies in four continents. Lancet 388(10046), 776-786 (2016)

55. Taghizadeh, N., Vonk, J.M., Boezen, H.M.: Lifetime smoking history and cause-specific mortality in a cohort study with 43 years of follow-up. PLoS ONE 11(4), e0153310 (2016)

56. Pirie, K., et al.: The 21 st century hazards of smoking and benefits of stopping: a prospective study of one million women in the UK. Lancet 381(9861), 133-141 (2013)

57. Stamatakis, E., et al.: Sitting time, physical activity, and risk of mortality in adults. J. Am. Coll. Cardiol. 73(16), 2062-2072 (2019)

58. Wang, X., et al.: Fruit and vegetable consumption and mortality from all causes, cardiovascular disease, and cancer: systematic 
review and dose-response meta-analysis of prospective cohort studies. BMJ 349, g4490 (2014)

59. Xi, B., et al.: Relationship of alcohol consumption to all-cause, cardiovascular, and cancer-related mortality in U.S. adults. J. Am. Coll. Cardiol. 70(8), 913-922 (2017)

60. NIAAA.: NIAAA Newsletter in NIAAA Newsletter 2004, Office of Research Translation and Communications, NIAAA, NIH: Online, p. 3

61. NM rendelet a kötelező egészségbiztosítás keretében igénybe vehetô betegségek megelőzését és korai felismerését szolgáló egészségügyi szolgáltatásokról és a szűrôvizsgálatok igazolásáról, in 51/1997. (XII. 18.) 1997, Magyar Közlöny 1997/114; Publication date: 18/12/1997: Hungary

62. A Nemzeti Népegészségügyi Központ módszertani levele a 2020. évi védőoltásokról. 2020, ÁNTSZ [National Public Health and Medical Officer Service]: Online

63. Zhang, C., Conrad, F.G.: Speeding in web surveys: the tendency to answer very fast and its association with straightlining. Surv. Res. Methods 8(2), 127-135 (2014)

64. Insignia Health.: Best practices for analysing PAM data, Insignia Health, Editor. Insignia Health, online

65. Mokkink, L.B., et al.: The COSMIN checklist for assessing the methodological quality of studies on measurement properties of health status measurement instruments: an international Delphi study. Qual. Life Res. 19(4), 539-549 (2010)

66. Prinsen, C.A.C., et al.: COSMIN guideline for systematic reviews of patient-reported outcome measures. Qual. Life Res. 27(5), 1147-1157 (2018)

67. Terwee, C.B., et al.: Rating the methodological quality in systematic reviews of studies on measurement properties: a scoring system for the COSMIN checklist. Qual. Life Res. 21(4), 651-657 (2012)

68. Lim, C.R., et al.: Floor and ceiling effects in the OHS: an analysis of the NHS PROMs data set. BMJ Open 5(7), e007765 (2015)

69. McGraw, K.O., Wong, S.P.: Forming inferences about some intraclass correlation coefficients. Psychol. Methods 1(1), 30-46 (1996)

70. Rosseel, Y.: lavaan: an R package for structural equation modeling. J. Stat. Softw. 48(2), 1-36 (2012)

71. Kaiser, H., Rice, J.: Little jiffy, mark IV. Educ. Psychol. Meas. 34(1), 111-117 (1974)

72. Námesztovszki, Z., et al.: The correlations between health behaviors and the use of health-preserving mobile applications in young adults. Acta Polytech. Hung. 17(2), 115-128 (2020)

73. Rasch, G.: Probabilistic Models for Some Intelligence and Attainment Tests. Danmarks Paedogogiske Institut, Copenhagen (1960)

74. van Buuren, S., Eekhout, I.: Child development with the D-score: turning milestones into measurement (2020). www.d-score.org

75. Linacre, J.: A User's Guide to Winsteps MINISTEP Rasch-Model Computer Programs. Winsteps, Chicago (2021)

76. Smith, R.: Polytomous mean-square fit statistics. Rasch Meas. Trans. 10(3), 516-517 (1996)

77. Breusch, T.S., Pagan, A.R.: A simple test for heteroscedasticity and random coefficient variation. Econometrica 47(5), 12871294 (1979)

78. Ramsey, J.: Tests for specification errors in classical linear leastsquares regression analysis. J. R. Stat. Soc. Ser. B 31(2), 350-371 (1969)

79. Hosmer, D.J., Lemeshow, S., Sturdivant, R.: Applied Logistic Regression, 3rd edn. Wiley, Hoboken (2013)

80. Fagerland, M., Hosmer, D.: A goodness-of-fit test for the proportional odds regression model. Stat. Med. 32, 2235-2249 (2013)

81. Fowles, J.B., et al.: Measuring self-management of patients' and employees' health: further validation of the patient activation measure (PAM) based on its relation to employee characteristics. Patient Educ. Couns. 77(1), 116-122 (2009)

82. Magnezi, R., Glasser, S.: Psychometric properties of the Hebrew translation of the patient activation measure (PAM-13). PLoS ONE 9(11), e113391 (2014)

83. Hendrikx, R.J.P., et al.: How to measure population health: an exploration toward an integration of valid and reliable instruments. Popul. Health Manag. 21(4), 323-330 (2018)

84. Laranjo, L., et al.: Translation and validation of the patient activation measure in Portuguese people with type 2 diabetes mellitus. Acta Med. Port. 31(7-8), 382-390 (2018)

85. Zeng, $\mathrm{H}$., et al.: Measuring patient activation in Chinese patients with hypertension and/or diabetes: reliability and validity of the PAM13. J. Int. Med. Res. 47(12), 5967-5976 (2019)

86. Bahrom, N.H., et al.: Validity and reliability of the patient activation measure(R) (PAM(R))-13 Malay version among patients with metabolic syndrome in primary care. Malays Fam. Physician 15(3), 22-34 (2020)

87. Stepleman, L., et al.: Validation of the patient activation measure in a multiple sclerosis clinic sample and implications for care. Disabil. Rehabil. 32(19), 1558-1567 (2010)

88. Kephart, G., et al.: The structural and convergent validity of three commonly used measures of self-management in persons with neurological conditions. Qual. Life Res. 28(2), 545-556 (2019)

89. Packer, T.L., et al.: The patient activation measure: a validation study in a neurological population. Qual. Life Res. 24(7), 1587-1596 (2015)

90. Ngooi, B.X., et al.: Validation of the patient activation measure (PAM-13) among adults with cardiac conditions in Singapore. Qual. Life Res. 26(4), 1071-1080 (2017)

91. Melby, K., et al.: Test-retest reliability of the patient activation measure-13 in adults with substance use disorders and schizophrenia spectrum disorders. Int. J. Environ. Res. Public Health 18(3), 1185 (2021)

92. Moljord, I.E., et al.: Psychometric properties of the Patient Activation Measure-13 among out-patients waiting for mental health treatment: a validation study in Norway. Patient Educ. Couns. 98(11), 1410-1417 (2015)

93. Ahn, Y.H., et al.: Psychometric properties of the Korean Version of the "Patient Activation Measure 13" (PAM13-K) in patients with osteoarthritis. Eval. Health Prof. 38(2), 255-264 (2015)

94. Eyles, J.P., et al.: Instruments assessing attitudes toward or capability regarding self-management of osteoarthritis: a systematic review of measurement properties. Osteoarthritis Cartil. 25(8), 1210-1222 (2017)

95. Eyles, J.P., et al.: Is the patient activation measure a valid measure of osteoarthritis self-management attitudes and capabilities? Results of a Rasch analysis. Health Qual. Life Outcomes 18(1), 121 (2020)

96. Roe, R., et al.: Outcomes in patient education programmes for people with rheumatic diseases: results from a Delphi process and a study of feasibility and responsiveness. Musculoskelet. Care 18(2), 195-203 (2020)

97. Cooper, V., et al.: Measuring empowerment among people living with HIV: a systematic review of available measures and their properties. AIDS Care 31(7), 798-802 (2019)

98. Cunha, C.M., et al.: Cultural adaptation and validation of the Brazilian Version of the patient activation measure-22 items. Rev. Bras Enferm 71(4), 1891-1898 (2018)

99. Skolasky, R.L., et al.: Psychometric properties of the patient activation measure among multimorbid older adults. Health Serv. Res. 46(2), 457-478 (2011)

100. Graffigna, G., et al.: Measuring patient activation in Italy: translation, adaptation and validation of the Italian version of the patient activation measure 13 (PAM13-I). BMC Med. Inform. Decis. Mak. 15, 109 (2015) 
101. Brenk-Franz, K., et al.: Validation of the German version of the patient activation measure 13 (PAM13-D) in an international multicentre study of primary care patients. PLoS ONE 8(9), e74786 (2013)

102. Hung, M., et al.: Psychometric assessment of the patient activation measure short form (PAM-13) in rural settings. Qual. Life Res. 22(3), 521-529 (2013)

103. Prey, J.E., et al.: Reliability and validity of the patient activation measure in hospitalized patients. Patient Educ. Couns. 99(12), 2026-2033 (2016)

104. Schmaderer, M., et al.: Psychometric properties of the patient activation measure in multimorbid hospitalized patients. J. Nurs. Meas. 23(3), 128-141 (2015)

105. Hellstrom, A., et al.: Validation of the patient activation measure in patients at discharge from hospitals and at distance from hospital care in Sweden. BMC Public Health 19(1), 1701 (2019)

106. Rademakers, J., et al.: Measuring patient activation in The Netherlands: translation and validation of the American short form Patient Activation Measure (PAM13). BMC Public Health 12, 577 (2012)

107. Leiner, D.J.: Too fast, too straight, too weird: non-reactive indicators for meaningless data in internet surveys. Surv. Res. Methods 13(3), 229-248 (2019)
108. Eysenbach, G., Wyatt, J.: Using the Internet for surveys and health research. J. Med. Internet Res. 4(2), E13 (2002)

109. Pál, V.: Egészségünk földrajza—területi különbséges a hazai egészségi állapotban. Magy. Tud. 178(2017/3), 311-321 (2017)

110. OECD/European Observatory on Health Systems and Policies, Hungary: Country Health Profile 2017.: OECD Publishing/European Observatory on Health Systems and Policies, Paris/Brussels (2017)

111. Expert Panel on Effective Ways of Investing in Health (EXPH).: Opinion on defining value in "value-based healthcare". European Commission, Brussels (2019)

112. Rotar, A.M., et al.: Shared decision making between patient and GP about referrals from primary care: does gatekeeping make a difference? PLoS ONE 13(6), e0198729 (2018)

113. OECD.: E.O.o.H. Systems, and Policies. Country Health Profile 2019, Hungary (2019)

Publisher's Note Springer Nature remains neutral with regard to jurisdictional claims in published maps and institutional affiliations. 